\title{
Adolescent social isolation and premature mortality in a Swedish birth cohort
}

\author{
Robin S. Högnäs ${ }^{1} \cdot$ Ylva B. Almquist $^{1} \cdot$ Bitte Modin $^{1}$
}

Published online: 22 November 2019

(C) The Author(s) 2019

\begin{abstract}
Research shows consistently that social ties are important for longevity, and they may be particularly important during adolescence. An absence of social ties, or social isolation, during adolescence may adversely affect long-term health and wellbeing. While prior research has examined associations between isolation from friends and long-term health, and having no siblings and mortality, no study (of which we are aware) considers jointly both the role of having no friends and no siblings, nor more generally with whom adolescents spend time, and the risk of premature mortality. This paper extends the literature by drawing on data from the Stockholm Birth Cohort Study to examine the association between different types of social isolation during adolescence (i.e., an absence of friends, siblings, and time with other adolescents) and the risk of premature mortality by midlife. Results suggest that having no siblings, being unliked at school, and spending (mostly) no time with other adolescents, increases the risk of premature mortality. The association between being unliked and premature mortality was attenuated by demographic and adolescent characteristics. Consistent with our expectations, net of a robust set of covariates, adolescents who had no siblings and mostly spent no time with other adolescents (i.e., isolates) were the group most vulnerable to premature mortality by midlife. However, this was only true for females.
\end{abstract}

Keywords Adolescent social isolation $\cdot$ Siblings $\cdot$ Friends $\cdot$ Premature mortality

\section{Introduction}

Social relationships are among the most important predictors of longevity. Decades of cross-disciplinary research has explored how social connections affect health outcomes across the life course (e.g., House et al. 1988; Umberson et al. 2010; Yang

Robin S. Högnäs

robin.hognas@su.se

1 Department of Public Health Sciences, Centre for Health Equity Studies, Stockholm University, Sveavägen 160, 10691 Stockholm, Sweden 
et al. 2016). During adolescence, ties between siblings and friends lie at the core of social interaction, and isolation from siblings and/or friends may have long-term negative consequences. Indeed, research suggests that different types of adolescent social isolation have both short-term consequences such as alcohol and drug use, and long-term consequences such as cardiovascular disease (e.g., Copeland et al. 2018; Caspi et al. 2006). Adolescents who have no siblings and who are unliked by, or disengaged from, peers at school may struggle with common problems that emerge during childhood (e.g., issues with parents, teachers, or school kids) as social support from these relationships tends to be protective (e.g., Hall-Lande et al. 2007). An absence of siblings and friends during adolescence may be a difficult social position that has long-term health consequences.

Research consistently shows that having someone to talk or turn to during times of need is important in adulthood (e.g., Shor et al. 2013) and may be particularly important during childhood and adolescence (Levitt et al. 1993; Rueger et al. 2016). Indeed, connections during adolescence potentially shape short- and long-term wellbeing. Whether at school, at home, or both, social isolation may increase behavioral, mental health, and physical health problems as adolescents age (Kreager 2004; HallLande et al. 2007; Yang et al. 2016), including the risk of mortality (BaranowskaRataj et al. 2017). While research shows a strong association between adult social isolation and mortality (Berkman and Syme 1979; House 2001; Holt-Lunstad et al. 2015), less is known about adolescent social isolation and premature mortality; and, no study (of which we are aware) has jointly considered adolescent friends and siblings. Consideration of one but not the other may over- or underestimate the health consequences of adolescent social isolation.

The current study extends the literature by jointly considering multiple types of adolescent social isolation, including having no siblings, and long-term health consequences. Specifically, we use data from the Stockholm Birth Cohort Study $(N=11,618)$ and Cox proportional hazard models to examine three questions. First, does adolescent social isolation increase the risk of premature mortality? Second, does the risk of premature mortality differ by the type of adolescent social isolation? Third, given well-known sex differences in all-cause mortality (Case and Paxson 2005; Oksuzyan et al. 2010), does the association between adolescent social isolation and premature mortality differ for females and males?

\section{Conceptual background and empirical research}

Over a century ago, Durkheim argued that social connectivity plays a prominent role in one's health (Durkheim 1951). His research showed that the level of connection between an individual and their surrounding social milieu is associated with suicide. Since Durkheim's seminal publication, research has underscored the importance of social ties for health (e.g., House et al. 1988; Cohen 2004; Umberson et al. 2010; Yang et al. 2016). Indeed, a large body of research explores both the benefits of social ties and the risks of social isolation. Benefits include, for example, protection from stress-related illnesses (e.g., Cohen and Wills 1985; Cohen and Pressman 
2004; Thoits 2010), and risks include health problems like inflammation and hypertension (Yang et al. 2016).

To understand better the link between adolescent isolation and premature mortality, it is necessary to consider social conditions and adjustments over the life course. The social convoy model (Kahn and Antonucci 1980; Levitt et al. 1993) does so, positing that a "person can be thought of as moving through the life cycle surrounded by a set of other people to whom he or she is related by the giving or receiving of social support" (Kahn and Antonucci 1980: 269). The social convoy captures ties and the dyadic relationships within which support is exchanged throughout one's life. Adolescence is a particularly important part of the social convoy to observe in reference to long-term health. Independence from parents and a need for peer-level relationships increase significantly during adolescence (e.g., Laursen 1996; Buhrmester 1996; Hall-Lande et al. 2007), and an absence of these ties may have enduring consequences. Adolescents confront hormonal, biological, and social challenges (see Crosnoe and Johnson 2011 for review), and siblings and friends likely provide support that parents cannot. Siblings and friends may relate better to one another's challenges (e.g., Hall-Lande et al. 2007), for example, with academic (e.g., grades) and social (e.g., boyfriends/girlfriends) issues.

Consequently, the social convoy for adolescents includes networks of siblings and/or friends with whom support often is exchanged (e.g., Levitt et al. 1993; Crosnoe and Johnson 2011). Siblings and friends may buffer against negative outcomes associated with the difficulties of growing up. Indeed, the stress buffering hypothesis posits that social support "eliminates or reduces effects of stressful experiences by promoting less threatening interpretations of adverse events and effective coping strategies" (Cohen 2004: 677). Isolated adolescents may not have access to such a buffer.

\section{Adolescent ties, health, and mortality}

The association between social relationships and health is persistent (e.g., House et al. 1988; Umberson et al. 2010; Yang et al. 2016). While no study (of which we are aware) has examined the association between adolescent isolation in terms of both friends and siblings and mortality, some studies have examined either friendships (e.g., Österberg and Modin 2008; Almquist 2011) or sibship size (e.g., Hart and Smith 2003; Baranowska-Rataj et al. 2017) and long-term health and mortality. Focusing first on siblings, sibship size is typically associated positively with mortality and explained partially by resource dilution (e.g., Blake 1981)—parents' time and money are divided across children (e.g., less help with homework, monitoring, educational expenses). Such parental investment may pay off as research suggests that only-children (versus children with siblings) have an education advantage; and education tends to protect against mortality (e.g., Batty et al. 2009; Falbo and Polit 1986). Moreover, while Downey and Condron (2004) find that preschool children with siblings have better social skills compared to only-children, later findings suggest that only-childrens' social deficits disappear by adolescence (Bobbitt-Zeher and Downey 2012). 
Despite educational advantages and the development of social skills, from a life course perspective, only-children may find it difficult to cope with social, economic, and health challenges as they age (e.g., divorce, unemployment, disease onset). Indeed, family members are sources of social support (Seeman 2000; Roslita et al. 2012) and siblings may be particularly important as these tend to be life-long relationships (Knipscheer and Van Tilburg 2013). While rivalries may characterise childhood sibling relationships, those who have no siblings may feel isolated at home. Research shows that sibling relationships ebb and flow over the life course, but siblings become increasingly important with age (e.g., White 2001; Guilley et al. 2005). Research further shows that only-children versus those with siblings have a higher risk of mortality (Baranowska-Rataj et al. 2017). Any disadvantages that come from having no siblings may be exacerbated for adolescents who have no friends or who spend no time with other adolescents.

A sense of belonging during adolescence is particularly important, and the literature suggests strongly that those who are isolated from friends are at risk of emotional and psychological problems and health risk behaviours. Copeland et al. (2018) argue that to understand better the effects of social isolation on health risk behaviours, it is important to examine the type of isolation experienced by adolescents. For example, the risks of alcohol and drug use may differ for those who retreat or disengage (i.e., nominate no classmates as a friend) from their school peers compared to those who are unliked (i.e., receive no friendship nomination from classmates) or who are outsiders (i.e., maintain friendships outside of their school). Indeed, their findings suggest that the type of isolation matters for health risk behaviours-disengaged outsiders were the highest risk group for substance use.

Studies have further found that low peer status (i.e., based on nominations from classmates) is negatively associated with health (e.g., Österberg and Modin 2008; Almquist 2011). Using data from the Aberdeen Child Development Survey, for example, Almquist (2011) finds that, between ages 7 and 11, females with two or fewer childhood friends and males with no friends report poorer health compared to males and females with three or more friends. Mental health patterns are similar, for example, more isolated versus integrated adolescents suffer from depression, suicide attempts, and low self-esteem (Hall-Lande et al. 2007). In addition, studies show that few adolescent friendships decrease health-related quality of life, and increase health care expenses in early adulthood (Mundt and Zakletskaia 2014), the onset of disease such as metabolic syndrome (Gustafsson et al. 2012), and risky health behaviours as adults (Almquist and Östberg 2012).

Data from the Stockholm Birth Cohort Study suggest that adolescents who are viewed by peers as undesirable workmates (i.e., unliked) are more likely to smoke in adulthood (Almquist and Östberg 2012), which increases the risk of life-threatening diseases such as heart disease, cancer, and among others, death (U.S. Department of Health and Human Services 2004). Almquist and Östberg rightly note that peer nominations may be due to academic performance rather than adolescent social integration. Thus, the association between no peer nominations and smoking is likely to be indirect, but the health consequences far-reaching. The risks of premature mortality associated with different types of friendship isolation (e.g., unliked, disengaged) 
may be exacerbated among adolescents who also have no siblings and subsequently negatively affect one's social convoy and risk of premature death.

\section{Sex differences}

Research consistently shows that life expectancy differs by sex-on average women live longer than men (e.g., Case and Paxson 2005) and this is true across Western and other countries (e.g., Oksuzyan et al. 2010). Research also suggests that the consequences of adolescent social isolation varies by sex. For example, Bearman and Moody (2004) find salient differences in the association between social isolation and mental health problems among adolescent girls and boys. Isolated adolescent girls, but not boys, were more likely to have suicidal thoughts. Österberg and Modin (2008) further found key sex differences in the association between peer status in school (i.e., a gradient from marginalisation to popular) and self-reported health over the life course. Using data from the Aberdeen Cohort Study, they found that while peer status in school was directly associated with health for girls, the association was indirect and operated through adult socioeconomic status for boys. The patterns of association between social isolation and adolescent substance use also varied for girls and boys (Copeland et al. 2018). Taken together, studies underscore the importance of sex differences in health-related outcomes associated with social isolation during adolescence.

\section{Other demographic, adolescent, and early adulthood characteristics}

Demographic characteristics and early life conditions First, children with lower birthweight (Kari et al. 2011) and children born to younger mothers may experience early life conditions that affect child development and adult health (e.g., Furstenberg et al. 1990). Next, lower versus higher socioeconomic groups are more likely to experience health problems, engage in risky health behaviours, and subsequently live shorter lives (Galobardes et al. 2004; Elo et al. 2014; Östergren 2017). Next, parental divorce may affect both sibship size and friendship networks, and research suggests that parental divorce is associated with poorer health among adult children (e.g., Thomas and Högnäs 2015). Moreover, parents who struggle with mental health problems may choose not to have more than one child, and parental mental health problems may be transmitted across generations (e.g., Gladstone et al. 2006), increasing the risk of premature mortality. In addition, parental health behaviours, and alcohol problems in particular, are associated positively with children's mental health problems and adult children's mental illness, drug use, and premature mortality (e.g., Christoffersen and Soothill 2003; Balsa et al. 2009).

Adolescent characteristics Next, school performance may be particularly important as it may be related to social isolation, educational attainment, and health and mortality (Crosnoe and Johnson 2011; Baranowska-Rataj et al. 2016). Also, it is important to adjust for behavioural problems as siblings and/or friends may serve as either a means of social control or conduits to truancy, for example. Both delinquency in peer networks and social isolation are associated with delinquent behavior (e.g., Kreager 2004; Haynie and Osgood 2005), and truancy in particular is 
associated with health risk behaviours in adulthood (e.g., Rocque et al. 2017). In addition, adolescent mental health is important as research suggests that it is likely to be associated with a range of negative outcomes, including mental and physical health problems in adulthood (e.g., Patel et al. 2007).

Early adulthood characteristics Ties to siblings and/or friends during teen years may influence educational decisions (e.g., Rosenqvist 2018) like attending a university. Research shows that, net of income, higher versus lower educated groups tend to live longer (e.g., Elo and Preston 1996). Moreover, there may be health advantages to long-term romantic unions. Indeed, meta-analyses and meta-regressions show that, compared to the continuously married, the risk of mortality increases for those who never marry, divorce, and lose a spouse to death (Roelfs et al. 2011; Shor et al. 2012a, b).

\section{The current study}

The current study extends the literature by examining the association between different types of social isolation (i.e., unliked or disengaged at school, no siblings, and mostly no time with other adolescents) during adolescence and premature death by midlife. Our study bridges two lines of empirical research that have separately considered the significance of siblings and friends in long-term health outcomes (e.g., Baranowska-Rataj et al. 2017; Yang et al. 2016). We argue that an examination of the consequences of being an only child without consideration of whether or not one has friends at school and vice versa, particularly during adolescence, is an important omission in the literature. Intuitively, adolescents who have siblings at home and friends at school are in better positions in terms of their social convoy, and thus are likely to have access to social support that may buffer against adverse health outcomes. Conversely, those who are isolates, i.e., who spend mostly no time with other adolescents, may be particularly vulnerable to short- and long-term adverse health outcomes (Caspi et al. 2006; Yang et al. 2016). Therefore, we expect to find-net of covariates - a positive association between social isolation and premature mortality. Given prior research (e.g., Bearman and Moody 2004), we further expect the association between social isolation and premature mortality to vary by sex.

\section{Methods}

\section{Data}

We use data from the Stockholm Birth Cohort Study (SBC) to examine the association between adolescent social isolation and premature mortality by midlife. The SBC was compiled in 2004 and 2005 using probability matching of two longitudinal data sources. The original data source was the Stockholm Metropolitan Study (SMS), which began collecting data on all 10-year olds and their families who lived in the Stockholm area in $1963(N=15,117)$. The SMS continued through 1985 , and its purpose was to study stratification and mobility processes prospectively. 
Using probability matching techniques, the SMS (which included $N=14,950$ living respondents by 1980) was subsequently merged with the Swedish Work and Mortality Database 1980-2009 (WMD), forming the SBC. Ninety-six percent of SMS participants were identified, and data were obtained about cohort members' lives through 2009, resulting in a sample size $N=14,294$ (see Stenberg et al. 2007 for more details).

Data from the SBC were appropriate for the current study because information about siblings, friends, and death was available between birth and midlife. The SBC allowed us to examine the association between adolescent social isolation and premature mortality, while adjusting for a robust set of covariates. As is the case with all observational studies, there were items missing on variables, including independent and dependent variables. Missing items on covariates was generally less than $20 \%$, so we retained more cohort members in our sample by using multiple imputation techniques (the ice command in Stata) to replace missing values for covariates. We only included observed cases for independent and dependent variables in all analyses. This approach resulted in an analytic sample of $N=11,618(n=5875$ females; and $n=5743$ males).

\section{Dependent variable}

The dependent variable is all-cause premature mortality (e.g., not specific to a certain cause) that occurs at or before midlife. We focus on premature mortality because we had information about deaths through 2009, or by age 56 . We censor cases where cohort members died prior to age 25 as this enabled us to adjust for education and marital status, measured at age 22 . Thus, the premature mortality risk period is between age 25 and age 56 .

\section{Independent variables}

The analyses included four primary independent variables used to capture social isolation types (i.e., no siblings, unliked, disengaged, and mostly spends no time with other adolescents). The first was children who did not have a sibling by the age of 18. A dummy indicator was used to capture adolescents without siblings, where $1=$ no siblings and $0=$ one or more siblings. Our measures of adolescents who were unliked or disengaged are consistent with prior research (e.g., Copeland et al. 2018), and are captured using questions included in the school study conducted when cohort members were age 13. First, adolescents were asked, "Who are your three best friends in class?" Being unliked was then measured using a dummy indicator where $1=$ zero votes as best friend from classmates and $0=$ one or more votes as best friend from classmates. Next, being disengaged was measured using the number of choices adolescents made in naming best friends in their class, where 1=named no best friends and $0=$ named at least one best friend.

For our final isolation type, also part of the school survey, cohort members were asked, "With whom do you spend most of your time?" Response categories included mostly with boys, mostly with girls, mostly with a group of boys and girls, mostly with adults, and I am mostly on my own. Our measure is a dummy 
indicator for which we collapse categories and where, $1=$ mostly no time other adolescents (mostly alone or mostly with adults) and $0=$ mostly time with other adolescents (mostly with girls, with boys, or with girls and boys). Factor analyses showed that being unliked, disengaged, and mostly no time with other adolescents did not load well together for one or more measures. Interitem correlations ranged from $r=.06$ to $r=.10$. The alpha reliability score for all three measures was .21 and ranged from .11 to .18 for different subsets of measures. Thus, we treated these as separate measures of adolescent social isolation.

\section{Covariates}

We adjusted our models for a robust set of factors from birth through early adulthood. First, demographic and early life conditions included a dummy indicator for cohort members' sex (i.e., $1=$ female; $0=$ male) given that females versus males tend to live longer. We included a dummy indicator for whether or not cohort members had a low birth weight, where $1=$ low birth weight, less than 2500 grams and $0=$ not low birth weight, more than 2500 grams. Next, children born to young mothers was captured using a dummy indicator where $1=$ mother age 20 or younger at birth and $0=$ mother older than age 20 at birth. We included three measures of socioeconomic status. First, occupational class of the household at cohort members' birth was measured using three dummy indicators for working (reference), middle, or upper class. Dummy indicators for household level of education were measured at age 7, where either none (reference), one, or two or more household members completed upper secondary school. Because fathers were primary household earners in the 1950s and 1960s, fathers' income at respondents' age 10 ranged from $1=1-20$ thousand kronor to $6=$ more than 100 thousand kronor. We included a dummy indicator for family structure, where $1=$ parents lived together at age 10 and $0=$ parents did not live together at age 10. Parents' mental health was measured using a dummy indicator where, $1=$ one or more parents had mental health problems and $0=$ no parent had mental health problems; and for alcohol problems where, $1=$ one or more parents had alcohol problems and $0=$ no parent had alcohol problems.

Next, we adjusted for several adolescent characteristics. School performance was measured using school marks during 6th grade, where $1=$ lowest school marks and $7=$ highest school marks. Truancy was measured using a dummy indicator, where $1=$ missed school but not ill and $0=$ did not miss school unless ill. Adolescent mental health was measured using a proxy variable for whether adolescents worried about the future where, $1=$ hardly ever worried to $5=$ often worried. Finally, we adjusted for education and marital status by age 22 (prior to the start of the risk period for premature mortality at age 25). Dummy indicators were included for whether one completed compulsory (reference), uppersecondary, or post-secondary school. Marital status included dummy indicators for married (reference), separated, divorced or widowed, and single/not married. Divorced, separated, and widowed were small groups and thus were collapsed into one category. 


\section{Analytic approach}

Our analyses begin with a description of the full SBC analytic sample also presented separately by sex. We then estimate Cox proportional hazard models, in which the numerator is a binary outcome indicating whether the cohort member had no siblings, for example, and the denominator is the number of personyears of exposure to the risk of all-cause premature mortality. Censored cases included those who died prior to the age of 25, which again, allowed us to adjust for education and marital status (measured at age 22). Global and detailed postestimation tests (based on Schoenfeld residuals) indicate no violation of the proportional hazard assumption. We include three models beginning with a baseline model estimating the risk of premature mortality by each type of adolescent social isolation (i.e., no siblings, unliked, disengaged, and spends no time with other teens). Model 2 adds demographic characteristics, early life conditions and adolescent characteristics; and Model 3 adds early adulthood characteristics. We then estimate Cox models with interaction terms for both our full analytic sample and separately by sex.

\section{Results}

\section{Descriptive}

We begin with Table 1, which shows the percentages, means, and standard deviations for each isolation type, covariates, and premature mortality for the full analytic sample and separately for females (51\%) and males (49\%). Starting with isolation types for the full sample, $13 \%$ had no siblings, $7 \%$ were unliked (or were not nominated as a best friend), $4 \%$ were disengaged (or nominated no best friends), and 6\% spent no time with other adolescents. In terms of demographic characteristics and early life conditions, few were born with low birth weight (3\%), and $7 \%$ were born to mothers age 20 or younger. More than three quarters were middle $(44 \%)$ or working (39\%) class. While the modal group were from middle class families (44\%), overall parental education was low (fewer than $30 \%$ had at least one parent with upper secondary education). Approximately $6 \%$ had a parent with mental health problems and $4 \%$ had a parent with alcohol problems.

In terms of adolescent characteristics, the average school performance was 4.0 (range $=1-7$ ), 30\% were truant from school at some point, and the average level of worries was 2.1 (range $=1-5$ ). In terms of early adulthood characteristics, more than three quarters of the analytic sample had at least an upper secondary education, and $38 \%$ had post-secondary education. Thus, it appears that by age 22, SBC cohort members had more education than their parents and most were unmarried (90\%). Approximately $5 \%$ died by age 56 . Overall, there were a few salient differences between females and males worth noting. First, while fewer than $10 \%$ of the full sample were unliked, $8 \%$ of males versus $5 \%$ of females were unliked. On the other hand, more females $(7 \%)$ than males $(5 \%)$ mostly spent no time with other adolescents. Even so, females (4.2) had higher school performance compared to males 
Table 1 Descriptive statistics for the full sample and shown separately by sex

\begin{tabular}{|c|c|c|c|c|c|c|}
\hline \multirow[t]{3}{*}{$\%$ the total sample } & Full & \multicolumn{2}{|c|}{ Females } & \multicolumn{3}{|c|}{ Males } \\
\hline & $100 \%$ & \multicolumn{2}{|l|}{$51 \%$} & \multicolumn{3}{|l|}{$49 \%$} \\
\hline & \multicolumn{3}{|c|}{$\%$ or $\mathrm{M}(\mathrm{SD})$} & & & \\
\hline \multicolumn{7}{|l|}{ Isolation types } \\
\hline No siblings & 13 & & 12 & & 13 & \\
\hline Unliked & 7 & & 5 & & 8 & \\
\hline Disengaged & 4 & & 4 & & 5 & \\
\hline Mostly no time with adolescents & 6 & & 7 & & 5 & \\
\hline \multicolumn{7}{|c|}{ Demographic characteristics and early life conditions } \\
\hline Low birth weight $(<2500 \mathrm{~g})$ & 3 & & 3 & & 3 & \\
\hline Mother $\leq$ age 20 at birth & 7 & & 7 & & 7 & \\
\hline \multicolumn{7}{|l|}{ HH occupational class } \\
\hline Working & 39 & & 39 & & 38 & \\
\hline Middle & 44 & & 44 & & 44 & \\
\hline Upper & 17 & & 17 & & 17 & \\
\hline \multicolumn{7}{|l|}{ Parental education } \\
\hline No graduate & 73 & & 73 & & 72 & \\
\hline One graduate & 21 & & 22 & & 21 & \\
\hline Two or more graduates & 6 & & 6 & & 6 & \\
\hline Fathers' income (range $=1-6$ ) & 1.9 & $(.9)$ & 1.9 & $(.9)$ & 1.9 & $(.8)$ \\
\hline Intact family at age 10 & 90 & & 90 & & 91 & \\
\hline Had mental health problems & 6 & & 6 & & 6 & \\
\hline Had alcohol problems & 4 & & 4 & & 4 & \\
\hline \multicolumn{7}{|l|}{ Adolescent characteristics } \\
\hline School performance $($ range $=1-7$ ) & 4.0 & $(1.3)$ & 4.2 & $(1.3)$ & 3.9 & $(1.3)$ \\
\hline Has been truant & 30 & & 27 & & 34 & \\
\hline Worries (range $=1-5$ ) & 2.1 & $(1.0)$ & 2.0 & $(1.0)$ & 2.0 & $(1.0)$ \\
\hline \multicolumn{7}{|c|}{ Early adulthood characteristics (by age 22) } \\
\hline \multicolumn{7}{|l|}{ Education } \\
\hline Compulsory & 17 & & 15 & & 19 & \\
\hline Upper secondary & 44 & & 45 & & 43 & \\
\hline Post-secondary & 39 & & 40 & & 37 & \\
\hline \multicolumn{7}{|l|}{ Marital/union status } \\
\hline Married & 9 & & 13 & & 4 & \\
\hline Divorced/separated/widowed & 1 & & 2 & & .5 & \\
\hline Unmarried/single & 90 & & 85 & & 95 & \\
\hline Premature death & 5 & & 4 & & 6 & \\
\hline$N$ & 11,618 & & 5875 & & 5743 & \\
\hline
\end{tabular}

(3.9) and males (34\%) versus females (27\%) were more likely to have been truant. Fewer males than females had post-secondary education, and fewer were married. However, $6 \%$ of males died prematurely compared to $4 \%$ of females. 


\section{Multivariate}

We turn now to our multivariate results. Table 2 shows hazard ratios predicting the risk of premature mortality by each isolation type (Model 1), and subsequently adds covariates (Models 2 and 3) based on the temporal order in which they occur. Starting with Model 1, net of all other isolation types, no siblings was associated significantly $(p<.05)$ and positively with the risk of premature mortality. The risk of premature death increased by approximately $31 \%$ for those without, versus with siblings. Similarly, net of all other types of isolation, both those who were unliked (hazard ratio or $\mathrm{HR}=1.41, p<.05$ ) and those who mostly spent no time with other adolescents $(\mathrm{HR}=1.38, p<.05)$ also had a higher risk of premature death. While the association between being disengaged and premature mortality was positive, suggesting that those who do not nominate classmates as best friends (versus those who do) have a higher risk of premature mortality, the HR was not statistically significant.

Once demographic characteristics, early life conditions, and adolescent characteristics were added in Model 2, the association between two isolation types, no siblings and mostly spent no time with adolescents, held and the magnitude increased for the latter isolation type (the significant HR increased from 1.38 to 1.52). On the other hand, the addition of covariates in Model 2 attenuated the association between unliked and premature mortality, both in terms of magnitude and significance (i.e., the significant HR dropped from 1.41 to 1.20 and not significant). When we add early adulthood characteristics in Model 3, the strength of the association between both no siblings and mostly spent no time with adolescents and premature mortality increased (both significant at $p<.05$ in Model 2 and $p<.01$ in Model 3). In Model 3, net of other types of isolation, the risk of premature mortality increased by $40 \%$ for those with no siblings versus those with at least one sibling; and the risk increased by $53 \%$ for those who mostly spent no time with adolescents (versus those who did). The increase in the strength of these associations may suggest that early adulthood characteristics partially suppress the association between these isolation types and premature mortality.

We shift now to our covariates, focusing on Model 3 for ease of interpretation. Beginning with demographic characteristics and early life conditions, as expected, the risk of premature mortality was significantly lower (by about 37\%) for females versus males. Those who were born to mothers age 20 or younger (versus to mothers age $20+)$ had a significantly higher risk of premature mortality $(H R=1.37)$. Low birth weight, SES background, and family structure (lived with both parents at age 10) were not associated significantly with premature mortality; however, mental health and alcohol problems were (1.36 and 2.03, respectively). Among adolescent characteristics, neither school performance, truancy, nor worries were significantly associated with premature mortality in Model 3. Finally, as expected, both education and marital status, net of all other covariates, were strongly and significantly associated with premature mortality. Those who had upper secondary and post-secondary (compared to compulsory levels of education) had a significantly lower risk of premature death $(.65$ and .45 , respectively, each at $p<.001)$. Moreover, the risk of premature mortality was significant and 2.57 times higher for the separated, divorced, 


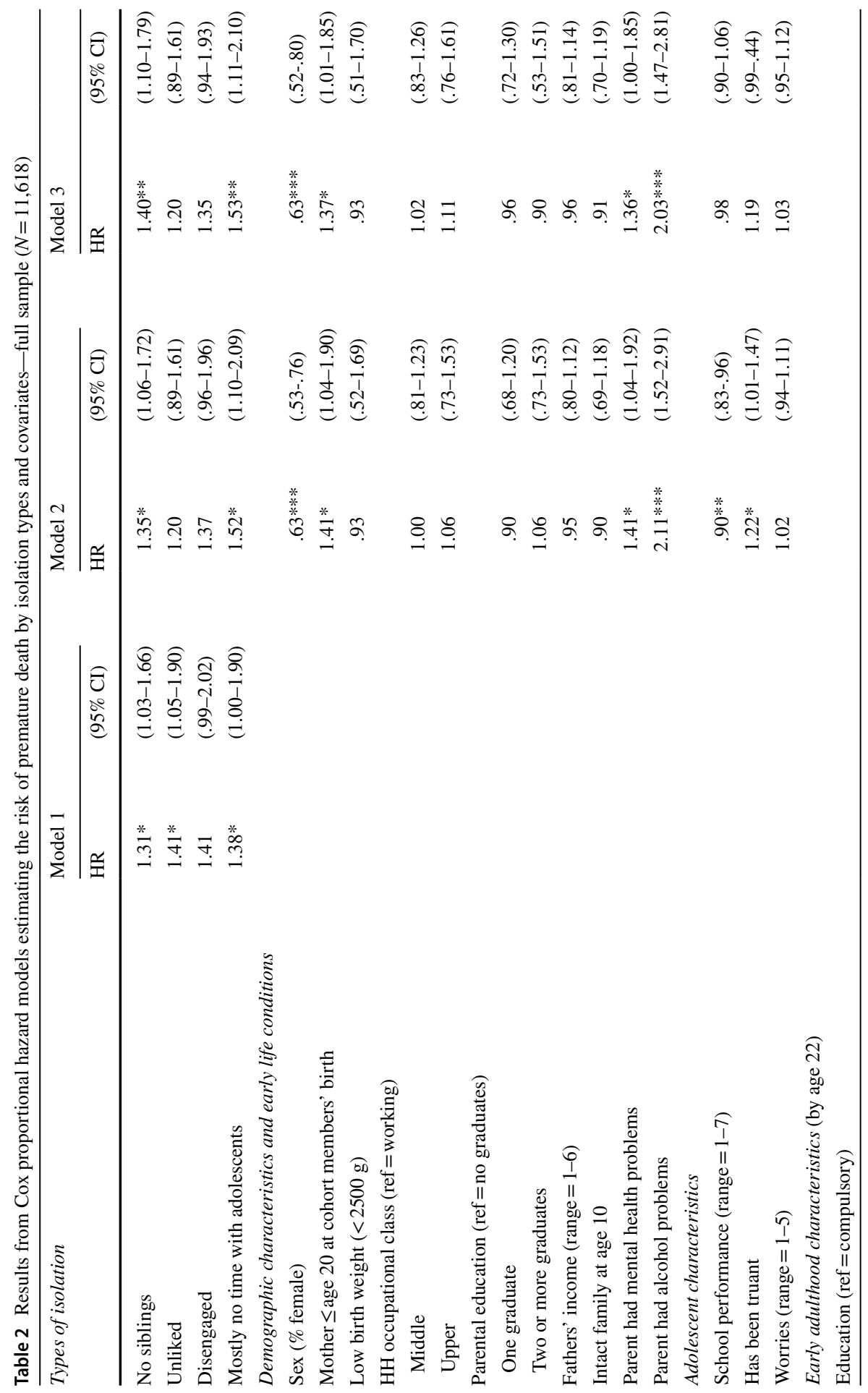




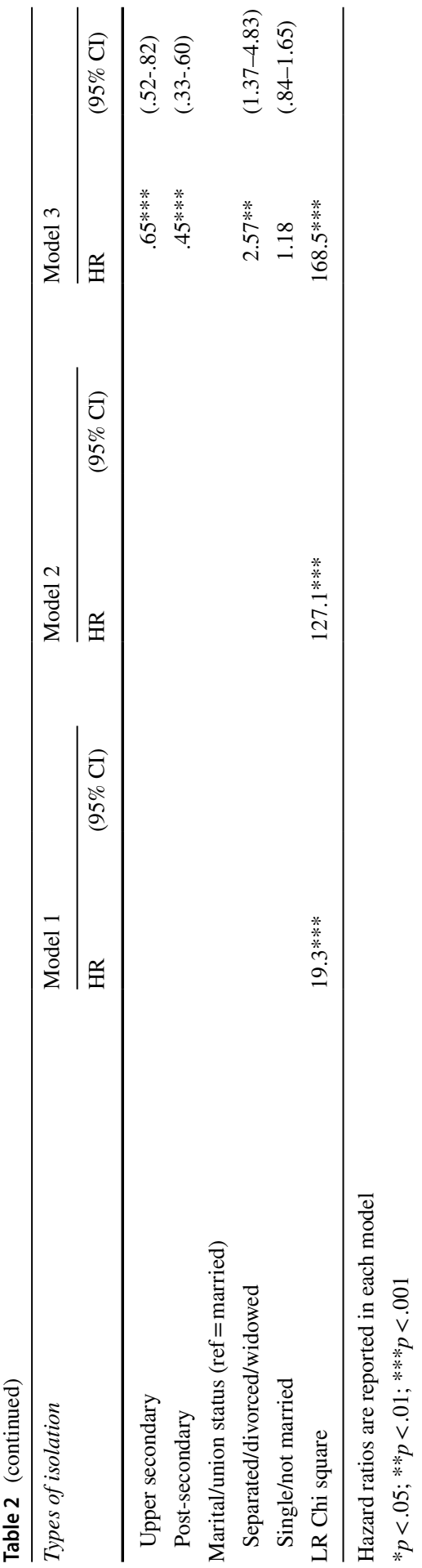


or widowed group compared to the married group; there was no significant difference between the unmarried/single and married groups.

We turn now to the results from our interaction models. ${ }^{1}$ As Model 3 in Table 2 shows, two isolation types-no siblings and mostly no time with adolescents-were associated significantly with premature mortality. Thus, we next examine variation in sibling status by time spent with adolescents and the risk of premature mortality. Table 3 shows the results of three, separately estimated interaction models, for the full sample, for females, and for males. Each model was estimated using Cox models and adjusted for all covariates. Starting with the column labeled "Full," the results suggests that, compared to those who both had siblings and spent time with other adolescents, the risk of premature mortality was 35\% $(p<.05)$ higher for those with no siblings, but who spent time with other adolescents. The results further showed that the risk of premature mortality was 2.67 times higher $(p<.01)$ for those who had neither siblings nor mostly no time with adolescents compared to those who had both (and is indeed significantly larger than the HR for those with no siblings but who spent time with adolescents). Taken together, these results suggest that both having siblings and spending time with adolescents is important; and those who have neither during adolescence may be vulnerable to premature mortality by midlife.

Next, given well-known differences in life expectancy for females and males, we estimated separate interaction models for each. Under the column heading "Females," the results were consistent with those shown in the full model; however, the magnitude of the association increased for both those who had no siblings but spent time with adolescents and those who had no siblings and mostly spent no time with adolescents. In fact, the risk of premature mortality was 4 times higher for females $(p<.01)$ who had neither during adolescence compared to those who had both.

We found no such significant associations for the male group. While the risk of premature mortality for males increased for all groups who had either no siblings (and) or no time with adolescents compared to adolescent males who had both, none of the HRs were statistically significant. These results suggest that social isolation during adolescence may be a risk factor for premature mortality for females but may not be as important for adolescent males. Other factors, however, were important for adolescent males. For example, being born to a young mother $(\mathrm{HR}=1.52$, $p<.05)$, having a parent with alcohol problems $(\mathrm{HR}=2.35, p<.001)$, and truancy $(\mathrm{HR}=1.33, p<.05)$ were each associated significantly with premature mortality for males, but not females. The corresponding survival curves for the models shown in Table 3 are shown in Fig. 1 and provide a more intuitive interpretation of these results.

\footnotetext{
1 While neither unliked nor disengaged were significant in our full models presented in Table 2, in supplemental analyses (not shown), we examined interactions between these types of adolescent isolation and sibling status. We found no significant interactions for the full sample, for females, nor for males.
} 


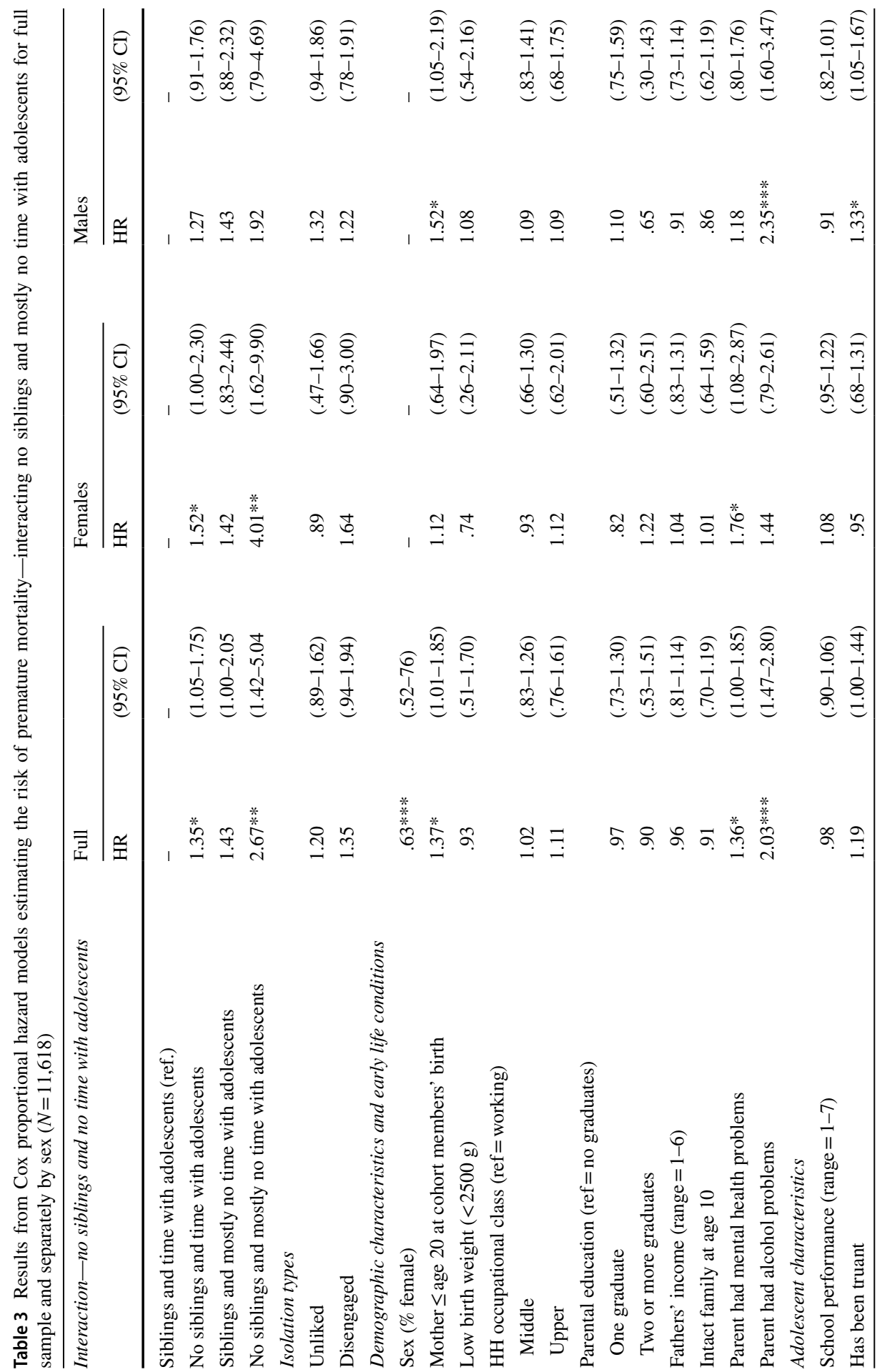




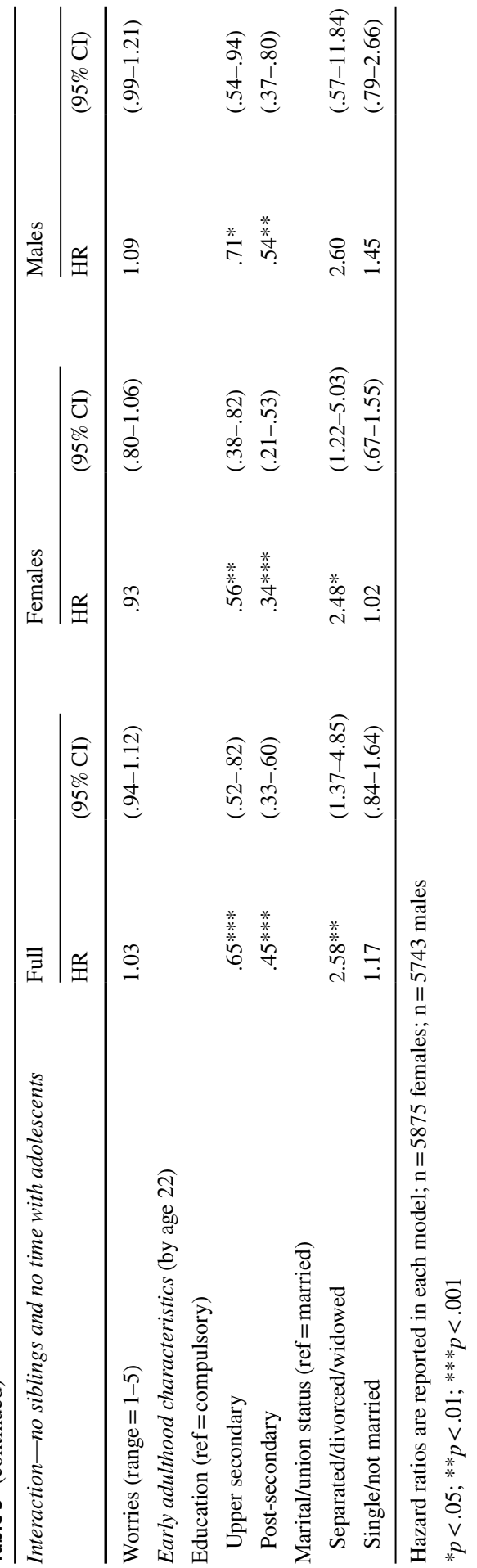




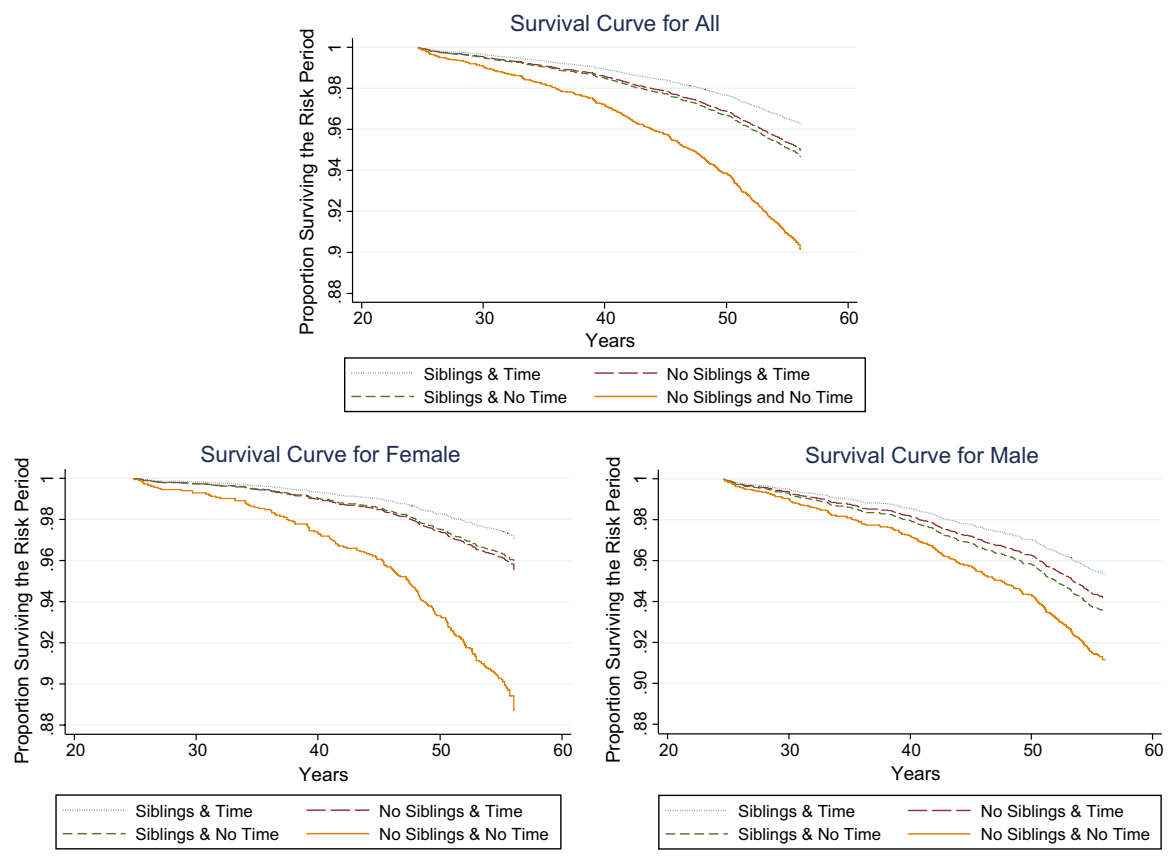

Fig. 1 Survival curves for interactions between sibling status and mostly spends no time with adolescents (from Table 3)

\section{Discussion}

This study provides new information about the association between adolescent social isolation and premature mortality. Prior studies emphasised separately the role of having no siblings or adolescent social isolation (and marginalisation) at school on adult health and mortality (e.g., Österberg and Modin 2008; Almquist 2011; Yang et al. 2016; Baranowska-Rataj et al. 2017). The current study extends the literature by examining the risk of premature mortality by additional types of adolescent social isolation - mostly no time with other adolescents and having no siblings. We further consider how interactions between different isolation types influence the risk of premature mortality, and variation by sex. We found important differences-disengagement at school was not associated significantly with premature mortality; however, the risk increased significantly among those who were unliked, who mostly spent no time with other adolescents, and were only children.

Demographic characteristics and early life conditions attenuated the association for being unliked, but having no siblings and spending no time with other adolescents was associated significantly with premature mortality net of a robust set of covariates measured from birth until early adulthood. In addition, the risk of premature mortality was 2.67 times higher for those who had no siblings and mostly spent no time with other adolescents (i.e., isolates) compared to those who had both. On the other hand, when we examined these associations separately for females and males, the significant association held only for females, for whom the risk of 
premature mortality was 4 times higher for isolates compared to those who had siblings and spent time with other adolescents. For males, the risk of premature mortality increased for all who did not have both siblings and time with other adolescents, but none of these associations were statistically significant.

An absence of social ties during adolescence or early in the life course may have lasting effects for females. Indeed, our findings are consistent with prior studies that have shown that the association between adolescent social isolation (or marginalisation) and health outcomes differs significantly for females and males (Bearman and Moody 2004; Copeland et al. 2018). Moreover, we recognise that ties to delinquent friends or perhaps those with whom one is truant, may introduce health risks over time (e.g., Rocque et al. 2017). However, the risk of premature mortality, at least for females, appears to be higher for those with no siblings, nor time with others in their age group; while, siblings and time with adolescents may be protective. Other factors appear more predictive of premature death for males. For example, the risk is $2.35(p<.001)$ times higher for males who had (versus did not have) a parent with an alcohol problem, $1.52(p<.05)$ times higher if males were born to a young mother, and $1.33(p<.05)$ times higher if they had been truant. The circumstances at home, combined with delinquent behavior, appear more important for adolescent males.

Our findings are also consistent with prior research suggesting that social isolation increases the risk of mortality (e.g., Hall-Lande et al. 2007; Gustafsson et al. 2012; Mundt and Zakletskaia 2014) and the importance of different types of adolescent isolation (e.g., Copeland et al. 2018). Research has underscored adolescent isolation in terms of peers at school, i.e., being unliked or receiving no friendship nominations from classmates, disengagement or nominating no friends, or being an "outsider" at school (Copeland et al. 2018). This includes adolescents who receive no nominations or nominate no one they may spend time with, for example, friends from a sports club, cousins, or with siblings. Thus, friendship nominations within one's school class may underestimate (i.e., for those with friends elsewhere) or overestimate (i.e., for those with siblings) the health risks associated with adolescent isolation. We extended the conceptualisation of isolation and indeed, our findings suggest that having no siblings and mostly spending no time with adolescents are risk factors for premature mortality. Extending the conceptualisation of adolescent isolation to include no siblings is important. While research suggests that those with no siblings have educational advantages (e.g., Batty et al. 2009) which tends to increase life expectancy (e.g., Elo and Preston 1996), there may be a social disadvantage of having no siblings that counteracts educational advantages, increasing the risk of mortality (e.g., Baranowska-Rataj et al. 2017).

Sibling relationships are biological connections, which are often life-long social connections (Knipscheer and Van Tilburg 2013) and research suggests that these relationships are important (for one's social convoy) (e.g., Seeman 2000; Roslita et al. 2012). Although siblings do not always maintain consistent connections, and may have stronger or weaker connections at different stages of the life course, sibling ties are important as one ages (e.g., White 2001; Guilley et al. 2005). Research further suggests that family ties provide social support; thus, to the extent that sibling relationships are consistent and supportive, they may be protective of disease 
onset or help through treatment once a disease is diagnosed. On the other hand, sibling age gaps and sex differences may be meaningful in terms of both adolescent isolation and whether or not relationships are consistent and supportive over time. In supplemental Cox analyses (not shown here), we explored a more nuanced measure of siblings - a set of dummy indicators that captured having no siblings and having siblings with 5-year age gaps and siblings of the same or different sex. The only group with a hazard ratio greater than 1 was those with no siblings, and no group was significantly different from those with same-sex siblings less than 5 years apart (reference group), likely due to smaller cell sizes. Although beyond the scope of the current study, more research exploring the conditions under which adolescents with siblings are (or feel) isolated and the associated health consequences is needed.

Friendships also contribute significantly to one's social convoy (e.g., Hall-Lande et al. 2007). The composition of one's friendship network likely changes from adolescence into adulthood, particularly amid life-altering events such as marriage (e.g., Kalmijn 2003) or divorce (e.g., Gerstel 1987). Although friendship trajectories are likely to be complex and due to data limitations are difficult to track as young people age (Crosnoe 2000), having friends during adolescence may signal that one will have them later on. Conversely, those who have no friendships during adolescence may have a higher risk of having fewer or no friends as they age, which may have health consequences.

As with all observational studies, this study is limited. First, our data did not allow us to examine changes in friendships or with whom adolescents spent their time between adolescence and midlife. Our results may be biased to the extent that those who are socially isolated during adolescence are not necessarily isolated over time. Even so, research suggests that adolescent social isolation may have lasting (Caspi et al. 2006; Yang et al. 2016), direct impacts on adult health, and perhaps especially for females (e.g., Österberg and Modin 2008). Moreover, we were not able to examine the quality of sibling relationships and friendships. If these relationships were stressful or of poor quality, for example, estimates of the association between adolescent isolation and premature mortality may be biased.

Future studies, where data allow, should examine the nature and quality of adolescent relationships over time and long-term health. Moreover, while this study focuses on the Swedish context, the association between social isolation and health appears consistent across a number of Western countries, including the U.S., Canada, Switzerland, the U.K., and others (e.g., Cohen 2004; Fry and Debats 2006; Guilley et al. 2005; Steptoe et al. 2013). Even so, the generous social safety net in Sweden and other Scandinavian countries (e.g., Esping-Andersen and Meyers 2008) potentially increases independence and decreases reliance on family and friends for support. If so, the long-term health consequences of adolescent isolation found in the current study may be worse in Western countries with weaker safety nets. Additional studies are needed to better understand cross-national differences in the association between adolescent social isolation and premature mortality.

Despite limitations, this study takes advantage of cohort data with a robust set of measures between birth and midlife to examine multiple types of adolescent social isolation and premature mortality. It is well-documented that social relationships are central to, and consistent predictors of, longevity. We know that those who lack 
social connections have, on average, more health problems and live shorter lives (e.g., House et al. 1988; Seeman 1996). Thus, understanding isolation at home and at school during early periods of the life course is important. While prior research has shown that an absence of friendships during adolescence can predict short- and long-term health (e.g., Hall-Lande et al. 2007; Österberg and Modin 2008), social isolation during adolescence is complex. Future life course studies aimed at understanding links between adolescent social isolation and health outcomes should account for how adolescents spend their time (e.g., alone, with adults, or with other adolescents) and the presence and quality of sibling relationships.

Acknowledgements Open access funding provided by Stockholm University. This project was funded by the Swedish Council for Health, Working Life and Welfare, Grant No. 2016-07148, PIs Bitte Modin and Ylva B. Almquist. Many thanks to Arzu Arat, Lauren Bishop, Alessandra Grotta, and especially Ulf Högnäs for helpful comments.

Open Access This article is distributed under the terms of the Creative Commons Attribution 4.0 International License (http://creativecommons.org/licenses/by/4.0/), which permits unrestricted use, distribution, and reproduction in any medium, provided you give appropriate credit to the original author(s) and the source, provide a link to the Creative Commons license, and indicate if changes were made.

\section{References}

Almquist, Y. (2011). Childhood friendships and adult health: Findings from the Aberdeen Children of the 1950s Cohort Study. European Journal of Public Health, 22(3), 378-383.

Almquist, Y., \& Östberg, V. (2012). Social relationships and subsequent health-related behaviors: Linkages between adolescent peer status and levels of adult smoking in a Stockholm Cohort. Addiction, $108,629-637$.

Balsa, A. I., Homer, J. F., \& French, M. T. (2009). The health effects of parental problem drinking on adult children. Journal of Mental Health Policy, 12, 55-66.

Baranowska-Rataj, A., Barclay, K., \& Kolk, M. (2017). The effect of number of siblings on adult mortality: Evidence from Swedish registers for cohorts born between 1938 and 1972. Population Studies, 71(1), 43-63.

Baranowska-Rataj, A., de Luna, X., \& Ivarsson, A. (2016). Does the number of siblings affect health in midlife? Evidence from the Swedish prescribed drug register. Demographic Research, 35(43), 1259-1302.

Batty, D., Wennerstad, K. M., Smith, G. D., Gunnel, D., Deary, I. J., Tynelius, P., et al. (2009). IQ in early adulthood and mortality by middle age: Cohort study of 1 million Swedish men. Epidemiology, 20(1), 100-109.

Bearman, P. A., \& Moody, J. (2004). Suicide and friendships among American adolescents. American Journal of Public Health, 94(1), 89-95.

Berkman, L. F., \& Syme, S. L. (1979). Social networks, host resistance, and mortality: A nine-year follow-up study of Alameda County residents. American Journal of Epidemiology, 109(2), 186-204.

Blake, J. (1981). Family size and the quality of children. Demography, 18(4), 421-442.

Bobbitt-Zeher, D., \& Downey, D. B. (2012). Number of siblings and friendship nominations among adolescents. Journal of Family Issues, 34(9), 1175-1193.

Buhrmester, D. (1996). Need fulfillment, interpersonal competence, and the developmental contexts of early adolescent friendship. In W. M. Bukowski, A. F. Newcomb, \& W. W. Hartup (Eds.), The company they keep: Friendship in childhood and adolescence (pp. 158-185). Cambridge: Cambridge University Press.

Case, A., \& Paxson, C. (2005). Sex differences in morbidity and mortality. Demography, 42(2), 189-214.

Caspi, A., Harrington, H., Moffitt, T. E., Milne, B. J., \& Poulton, R. (2006). Socially isolated children 20 years later. Archives of Pediatric and Adolescent Medicine, 160, 805-811. 
Christoffersen, M. N., \& Soothill, K. (2003). The long-term consequences of parental alcohol abuse: A cohort study of children in Denmark. Journal of Substance Abuse and Treatment, 25, 107-116.

Cohen, S. (2004). Social relationships and health. American Psychologist, 59(8), 676-684.

Cohen, S., \& Pressman, S. (2004). The stress-buffering hypothesis. In N. Anderson (Ed.), Encyclopedia of health and behavior. Thousand Oaks, CA: Sage Publications.

Cohen, S., \& Wills, T. A. (1985). Stress, social support, and the buffering hypothesis. Psychological Bulletin, 98(2), 310-357.

Copeland, M., Fisher, J. C., Moody, J., \& Feinberg, M. E. (2018). Different kinds of lonely: Dimensions of isolation and substance use in adolescence. Journal of Youth and Adolescence, 47, 1755-1770.

Crosnoe, R. (2000). Friendships in childhood and adolescence: The life course and new directions. Social Psychology Quarterly, 63(4), 377-391.

Crosnoe, R., \& Johnson, M. K. (2011). Research on adolescence in the twenty-first century. Annual Review of Sociology, 37, 439-460.

Downey, D. B., \& Condron, D. J. (2004). Playing well with others in kindergarten: The benefit of siblings at home. Journal of Marriage and Family, 66(2), 333-350.

Durkheim, E. (1951). Suicide: A study in sociology. New York, NY: The Free Press.

Elo, I., \& Preston, S. H. (1996). Educational differentials in mortality: United States, 1979-1985. Social Science and Medicine, 42(1), 47-57.

Elo, I. T., Martikainen, P., \& Myrskylä, M. (2014). Socioeconomic status across the life course and all-cause and cause-specific mortality in Finland. Social Science and Medicine, 119, 198-206.

Esping-Andersen, G., \& Meyers, J. (2008). The welfare state and redistribution. In D. B. Grusky (Ed.), Social stratification: Class, race, and gender in sociological perspective (pp. 52-58). Boulder, CO: Westview Press.

Falbo, T., \& Polit, D. F. (1986). Quantitative review of the only child literature: Research evidence and theory development. Psychological Bulletin, 100(2), 176-189.

Fry, P. S., \& Debats, D. L. (2006). Sources of life strengths as predictors of late-life mortality and survivorship. The International Journal of Aging and Human Development, 62(4), 303-334.

Furstenberg, F. F., Jr., Levine, J. A., \& Brooks-Gunn, J. (1990). The children of teenage mothers: Patterns of early childbearing in two generations. Family Planning Perspectives, 22(2), 54-61.

Galobardes, B., Lynch, J. W., \& Davey Smith, G. (2004). Childhood socioeconomic circumstances and cause-specific mortality in adulthood: Systematic review and interpretation. Epidemiologic Reviews, 26(1), 7-21.

Gerstel, N. (1987). Divorce and stigma. Social Problems, 34(2), 172-186.

Gladstone, B. M., Boydell, K. M., \& McKeever, P. (2006). Recasting research into children's experiences of parental mental illness: Beyond risk and resilience. Social Science and Medicine, 62, 2540-2550.

Guilley, E., Stephanie, P., Spini, D., d'Epinay, C. L., Herrmann, F., \& Michel, J.-P. (2005). Association between social relationships and survival of Swiss octogenerians. A five-year prospective population-based study. Aging Clinical and Experimental Research, 17(5), 419-425.

Gustafsson, P. E., Janlert, U., Theorell, T., Westerlund, H., \& Hammarström, A. (2012). Do peer relations in adolescence influence health in adulthood? Peer problems in the school setting and the metabolic syndrome in middle-age. PLoS ONE, 7(6), e39385.

Hall-Lande, J. A., Eisenberg, M. E., Christenson, S. L., \& Neumark-Sztainer, D. (2007). Social isolation, psychological health, and protective factors in adolescence. Adolescence, 42(166), 265-286.

Hart, C. L., \& Smith, G. D. (2003). Relation between number of siblings and adult mortality and stroke risk: 25 year follow up of men in the Collaborative study. Journal of Epidemiology and Community Health, 57, 385-391.

Haynie, D. L., \& Osgood, D. W. (2005). Reconsidering peers and delinquency: How do peers matter? Social Forces, 84(2), 1109-1130.

Holt-Lunstad, J., Smith, T. B., Baker, M., Harris, T., \& Stephenson, D. (2015). Loneliness and social isolation as risk factors for mortality: A meta-analytic review. Perspectives on Psychological Science, 10(2), 227-237.

House, J. (2001). Social isolation kills, but how and why? Psychosomatic Medicine, 63, 273-274.

House, J. S., Landis, K., \& Umberson, D. (1988). Social relationships and health. Science, 241, $540-545$. 
Kahn, R. L., \& Antonucci, T. C. (1980). Convoys over the life course: Attachment, roles, and social support. In P. B. Baltes \& O. Brim (Eds.), Life span development and behavior (Vol. 3, pp. 253-286). New York, NY: Academic Press.

Kalmijn, M. (2003). Friendship networks over the life course: A test of the dyadic withdrawal hypothesis using survey data on couples. Social Networks, 25, 231-249.

Kari, R. R., Vatten, L. J., Baker, J. L., Jameson, K., Sovio, U., Kajantie, E., et al. (2011). Birthweight and mortality in adulthood: a systematic review and meta-analysis. International Journal of Epidemiology, 40(3), 647-661.

Knipscheer, K., \& van Tilburg, T. (2013). Generational contact and support among late adult siblings within a verticalized family. In M. Siverstein \& R. Giarrusso (Eds.), Kinship and cohort in an aging society: From generation to generation (pp. 59-76). Baltimore, MD: The Johns Hopkins University Press.

Kreager, D. A. (2004). Strangers in the halls: Isolation and delinquency in school networks. Social Forces, 83(1), 351-390.

Laursen, B. (1996). Closeness and conflict in adolescent peer relationships: Interdependence with friends and romantic partners. In W. M. Bukowski, A. F. Newcomb, \& W. W. Hartup (Eds.), The company they keep: Friendship in childhood and adolescence (pp. 186-210). Cambridge: Cambridge University Press.

Levitt, M. J., Guacci-Franco, N., \& Levitt, J. L. (1993). Convoys of social support in childhood and early adolescence. Developmental Psychology, 29(5), 811-818.

Mundt, M., \& Zakletskaia, L. I. (2014). That's what friends are for: Adolescent peer social status, health-related quality of life and healthcare costs. Applied Health Economics and Health Policy, 12(2), 191-201.

Oksuzyan, A., Crimmins, E., Saito, Y., O’Rand, A., Vaupel, J. W., \& Christensen, K. (2010). Crossnational comparison of sex differences in health and mortality in Denmark, Japan, and the US. European Journal of Epidemiology, 25, 471-480.

Österberg, V., \& Modin, B. (2008). Status relations in school and their relevance for health in a life course perspective: Findings from the Aberdeen children of the 1950's Cohort Study. Social Science and Medicine, 66(4), 835-848.

Östergren, O. (2017). Understanding the educational gradient in mortality. Stockholm: Stockholm University.

Patel, V., Flisher, A. J., Hetrick, S., \& McGorry, P. (2007). Mental health of young people: A global public-health challenge. Lancet, 369, 1302-1313.

Rocque, M., Jennings, W. G., Piquero, A. R., Ozkan, T., \& Farrington, D. P. (2017). The importance of school attendance: Findings from the Cambridge study in delinquent development on the lifecourse effects of Truancy. Crime \& Delinquency, 63(5), 592-612.

Roelfs, D. J., Shor, E., Kalish, R., \& Yogev, T. (2011). The rising risk of mortality for singles: Metaanalyses and meta-regression. American Journal of Epidemiology, 174(4), 379-389.

Rosenqvist, E. (2018). Two functions of peer influence on upper-secondary education application behavior. Sociology of Education, 91(1), 72-89.

Roslita, M., Sarela, J., \& Kawachi, I. (2012). The forgotten griever: A nationwide follow-up study of mortality subsequent to the death of a sibling. American Journal of Epidemiology, 176(4), 338-346.

Rueger, S. Y., Malecki, C. K., Pyun, Y., Aycock, C., \& Coyle, S. (2016). A meta-analytic review of the association between perceived social support and depression in childhood and adolescence. Psychological Bulletin, 142(10), 1017-1067.

Seeman, T. E. (1996). Social ties and health: The benefits of social integration. Annals of Epidemiology, $6(5), 442-451$.

Seeman, T. E. (2000). Health promoting effects of friends and family on health outcomes in older adults. American Journal of Health Promotion, 14(6), 362-370.

Shor, E., Roelfs, D. J., Bugyi, P., \& Schwartz, J. E. (2012a). Meta-analysis of marital dissolution and mortality: Reevaluating the intersection of gender and age. Social Science and Medicine, 75, 46-59.

Shor, E., Roelfs, D. J., Curreli, M., Clemow, L., Burg, M. M., \& Schwartz, J. E. (2012b). Widowhood and mortality: A meta-analysis and meta-regression. Demography, 49, 575-606.

Shor, E., Roelfs, D. J., \& Yogev, T. (2013). The strength of family ties: A meta-analysis and metaregression of self-reported social support and mortality. Social Networks, 35(4), 626-638. 
Stenberg, S.-Å., Vågerö, D., Österman, R., Arvidsson, E., Von Otter, C., \& Janson, C.-G. (2007). Stockholm Birth Cohort Study 1953-2003: A new tool for life-course studies. Scandinavian Journal of Public Health, 35, 104-110.

Steptoe, A., Shankar, A., Demakakos, P., \& Wardle, J. (2013). Social isolation, loneliness, and allcause mortality in older men and women. Proceeding of the National Academy of Sciences, $110(15), 5797-5801$.

Thoits, P. A. (2010). Stress and health: Major findings and policy implications. Journal of Health and Social Behavior, 51(Extra Issue), S41-S53.

Thomas, J. R., \& Högnäs, R. S. (2015). The effect of parental divorce on the health of adult children. Longitudinal and Life Course Studies, 6(3), 279-302.

Umberson, D., Crosnoe, R., \& Reczek, C. (2010). Social relationships and health behavior across the life course. Annual Review of Sociology, 36, 139-157.

U.S. Department of Health and Human Services. (2004). The health consequences of smoking: A report of the surgeon general. United States Department of Health and Human Services, Centers for Disease Control and Prevention, National Center for Chronic Disease Prevention and Health Promotion, Office on Smoking and Health.

White, L. (2001). Sibling relatinships over the life course: A panel analysis. Journal of Marriage and Family, 63(2), 555-568.

Yang, Y. C., Boen, C., Gerken, K., Li, T., Schorpp, K., \& Harris, K. M. (2016). Social relationships and physiological determinants of longevity across the human life span. Proceedings of the National Academy of Sciences, 113(3), 578-583.

Publisher's Note Springer Nature remains neutral with regard to jurisdictional claims in published maps and institutional affiliations. 